\title{
A note on the texts
}

In keeping with Radclyffe Hall's wishes, Una Troubridge destroyed most, but not all, of her partner's papers after her death in 1943. When Troubridge herself died in Rome in 1963, some of these remaining materials were bequeathed to her friend, the opera singer Nicola Rossi-Lemeni, who passed them on to her son, Alessandro Rossi-Lemeni. These manuscripts were kept in two trunks in a basement in Rome before they were acquired and catalogued by the Harry Ransom Center in Austin, Texas, in 1997. The archive comprises a diverse range of materials, including early drafts of published novels and short stories; unpublished novels and short fiction; notes and sketches; letters and publicity materials; and some of Troubridge's diaries.

This volume presents a selection of these manuscripts. It includes ten previously unpublished short stories and Hall's unfinished novel 'The World'. It also contains early drafts of Hall's short story 'Miss Ogilvy Finds Herself' (1934) and of the war section in The Well of Loneliness (1928). Choosing archival materials for publication is inevitably a subjective process that warrants explanation. The state of some surviving manuscripts made it impossible to transcribe them for publication. For example, the Harry Ransom Center holds a handwritten draft of Hall's only known play, which is so heavily damaged by water and mould that it is illegible in large parts. Hall's idiosyncratic writing and spelling also made some of the existing manuscripts difficult and, at times, impossible to read and transcribe. I have mentioned some of the manuscripts that could not be published in the present volume in my Introduction; other materials that are held at the Harry Ransom Center and the Lovat Dickson Archive at the National Archives of Canada in Ottawa and that remain unpublished are discussed in the most recent biographies of Hall by Sally Cline and Diana Souhami and in Richard Dellamora's Radclyffe Hall: A Life in the Writing (2011). My editorial decisions were also guided by Hall herself: she hoped to publish most of the short fiction included in the present volume and prepared polished drafts that are suitable for publication. Exceptions such as 'The Modern Miss Thompson' or 'The World', which were not revised for publication, are included, because they offer new insights into Hall's engagement with themes and topics that are of scholarly interest. Similarly, the early drafts of published texts like 'Miss Ogilvy Finds Herself' and The Well of Loneliness are selected due to their relevance to scholarship. 
Dating Hall's manuscripts poses serious challenges to the editor, as the materials I consulted arrived at the Harry Ransom Center in no particular order. I have included all available information in the Introduction or in the Editorial notes at the end of the volume. These notes also detail how many drafts of each text survive and in what form. In cases where multiple versions exist, I have drawn on internal or external evidence to select the final surviving typescript. With regard to 'The World', I have selected the longest existing draft. The more complicated evolution of the unpublished draft of 'Miss Ogilvy Finds Herself' is detailed in the Introduction.

In preparing these texts for publication, my aim was to present a readable text. Most of the typescripts contain only minor revisions and corrections, which have been incorporated silently in the transcripts published here. Exceptions are mentioned in the Introduction or Notes. Hall struggled very seriously with orthography, and I have silently corrected most misspellings and standardised variant spellings. I have also, for the most part, corrected and standardised without comment capitalisation, hyphenation and punctuation (e.g. 'Thomas Cook's' for Thomas Cooks'). Commonly used abbreviations and contractions have been spelt out (e.g. 'and' for ' $\&$ '). Square brackets are reserved for editorial use and indicate gaps, doubtful readings of illegible text and wording supplied by editorial conjecture. [?] stands for an illegible word. A word in square brackets followed by a question mark indicates a word supplied by editorial conjecture. Finally, a bracketed word without a question mark represents an editorial addition. 